BUSINESS

\section{Nuclear Trading}

A pleasant past and a promising future characterizes the annual reports of British Nuclear Fuels and The Radiochemical Centre, published last week.

These two off-shoots of the United Kingdom Atomic Energy Authority have just celebrated their second year as independent entities, and both are now operating at a healthy profit. But British Nuclear Fuels report is noteworthy chiefly for the news that the government is to advance the greater part of the capital required to build the gas centrifuge uranium enrichment plant that is currently planned for completion in 1976. Under a tripartite agreement between Britain, West Germany and the Netherlands two demonstration plants designed to produce 200 tonnes a year are being built at Capenhurst and Almelo to be run by Urenco and Centec, the two companies set up under the agreement to construct the plants. If all goes well enrichment capacity will be increased to 2,000 tonnes a year by 1980 .

As Sir John Hill, BNFL's chairman, points out in the report, the capital sum -which is undisclosed but is thought to total between $£ 50$ and $£ 60$ million-is substantial in relation of BNFL's earnings, which last year rose $£ 1$ million to $£ 65$ million. In spite of the three way sharing of construction costs the sum is still large; under the terms of the guarantee the government will be repaid out of the profits from the undertaking.

The report also states that BNFL will not be taking part in the second stage of the French Eurodif studies of diffusion plant. France is eager to build a large diffusion plant, but the economics of the operation are such that only one large plant that is run at almost full load can be built. BNFL took part in the first stage of the international studies of such a plant but declare that "the first year's work ... confirmed the company in its view that the centrifuge process was likely to offer better prospects of producing enrichment for the European and world market at competitive prices in the medium and long term. The company is not taking part in the second year of the study".

The report also shows that BNFL's profits remained static at $£ 10$ million although the percentage profit rose by $1.7 \%$ to $15.8 \%$. Sales only increased £1.6 million, chiefly due to the lack of new orders for nuclear power stations and the fact that the Advanced Gas Cooled Reactors are not yet on load. BNFL managed to sell some reload fuel for light water reactors to the Netherlands, "but a major expansion in this field is unlikely unless water reactors are introduced into the UK power programme", according to Sir John Hill.
The Radiochemical Centre for its part increased its sales by over $25 \%$ to $£ 7.6$ million. The profit before tax rose $61 \%$ to $£ 1.3$ million, representing a return on capital after loan interest charges of $28 \%$. Seventy per cent of the centre's business is overseas, the largest growth area being radiopharmaceuticals.

Considerable investment in new facilities is planned over the next few years, and the centre's chairman, Sir Charles Cunningham, states that the company's staff structure-essentially that inherited from the United Kingdom Atomic Energy Authority-is to be revamped "to meet the needs of a commercial company operating in world markets".

\section{ECOLOGY \\ Defecting the Changes}

from a Correspondent

How is environmental change (brought about by man's activities or by natural causes) to be assessed? This broad question received a detailed examination in London recently when the Natural Environment Research Council held a one day seminar under the title the detection and assessment of significant biological change.

The meeting's conciusion seemed chiefly to be that there is a great need for more background data, more scientific effort and, of course, more resources. But on the way to that conclusion some interesting points were raised.

Mr R. J. H. Beverton, secretary of NERC, highlighted the problem by pointing out that one of the chief difficulties lies in the diversity of the living world and in its, mostly unrecorded, variability. As many man-made influences are enhancements of natural ones it follows that their effects are difficult to detect and quantify. It is often difficult, $\mathrm{Mr}$ Beverton said, to distinguish between the signal and the background noise.

Many monitoring programmes are already under way whose objective is to detect adverse trends. The methods employed are almost always physical or chemical-for instance measuring temperature, salinity, dissolved oxygen or suspended solids. The question is how important are the changes to biological communities, and how can these fluctuations be detected before damage occurs?

Dr J. W. G. Lund of the Freshwater Biological Association declared that while it is often possible, with hindsight, to explain changes that have already taken place in the freshwater environment, it is quite a different matter to predict them. Often, he said, we do not even know what should be observed. This view was supported by $\mathrm{Dr}$ J. M. Hellawell who, as a NERC research fellow, has examined several schemes for biological monitoring of rivers. He concluded that the schemes he studied were often inaccurate and sometimes misleading when taken on their own.

Predicting changes on land seems little easier. Schemes for aphid and moth monitoring that have been run on a national scale for a number of years were described by Dr L. R. Taylor of the Rothamsted research station. Again, changes are easily detected in the populations, but it is so far impossible to distinguish between short and long term climatic changes, alterations in land use or other man-made influences.

In the marine environment changes cannot yet be predicted accurately, while on the shoreline too little is known about the biological interactions in shore communities to allow monitoring to take place.

Other monitoring programmes run into further difficulties over the subjec. tive element introduced by the observers who provide the data-for example the monitoring of bird populations by the British Trust for Ornithology and the mapping of plant species from Monks Wood research station.

For monitoring to be effective it may, in the end, have to concentrate on a limited closely defined objective. Nonetheless it is still hoped that some schemes can be conceived to provide an overall index of environmental quality. In response to this possibility NERC has just appointed two working groups to examine biological surveillance in the marine and terrestrial environments.

\section{SPACE \\ Mars 6 Stirs Speculation}

from our Cosmology Correspondent

THE launch of Mars 6 on August 6, just one day before the recent "window" for Mars launches closed, makes the present series of probes the first Soviet triple venture to the red planet. Together with the wording of official communiques about the launch, this has encouraged renewed speculation that Mars 6 might be the awaited soft lander, possibly carrying a "Marsokhod".

While Mars 4 and Mars 5 are described as being "analogous in structure and purpose" (see Nature, 244, 249 ; 1973), Mars 6 is different in design from the two probes now three weeks ahead of it on the way to Mars, according to TASS. The official releases say that Mars 6 will use Mars 4 in carrying out its exploration, a choice of phrase which has been taken as hinting strongly that Mars 6 will carry out a landing on the planet and use Mars 4 to relay messages back to Earth. In that case, Mars 5 might well incorporate a backup facility for Mars 4. 